\title{
Regioselective mononitration of aromatic compounds by zeolite/dinitrogen tetroxide/air in a solvent-free system
}

\author{
Keith Smith,* Saeed Almeer and Christelle Peters \\ Centre for Clean Chemistry, Department of Chemistry, University of Wales Swansea, Swansea, UK \\ SA2 8PP. E-mail: k.smith@swansea.ac.uk
}

\author{
Received (in Cambridge, UK) 2nd October 2001, Accepted 22nd October 2001 \\ First published as an Advance Article on the web 28th November 2001
}

\begin{abstract}
Nitration of aromatic compounds using a zeolite catalyst and a combination of dinitrogen tetroxide and air in a sealed system leads to high yields and para-selectivities in a clean, solvent-free process.
\end{abstract}

Electrophilic aromatic substitution reactions are of considerable importance in the production of fine chemicals. However, many traditional processes suffer serious disadvantages, including low selectivity for the desired product and the requirement for large quantities of mineral or Lewis acids as activators. Such acids cause corrosion and generate large volumes of spent reagents. Major efforts are therefore being made to develop processes with lower environmental impact.

Inorganic solids offer significant benefits by providing effective catalysis and, in some cases, enhanced selectivity. ${ }^{1}$ For example, in our own research we have utilised zeolites to enhance the para-selectivity in chlorination, ${ }^{2}$ bromination, ${ }^{3}$ acylation $^{4}$ and methanesulfonylation ${ }^{5}$ reactions of simple aromatic substrates. In addition, such solids are easily recycled.

Aromatic nitration is particularly important since nitro compounds are versatile feedstocks for a range of industrial products, including pharmaceuticals, agrochemicals, dyestuffs, and explosives. Traditional nitration with a mixture of nitric and sulfuric acids ${ }^{6}$ is notoriously unselective for nitration of substituted compounds, and disposal of the spent liquors presents a serious environmental concern. ${ }^{7}$ Consequently, several alternative methods for aromatic nitrations have been developed. ${ }^{8-15}$

At present, the best combination of high yield, high paraselectivity and low solvent use is nitric acid, zeolite HBEA $(\mathrm{H} \beta)$ and acetic anhydride (for moderately active aromatics) ${ }^{12}$ or trifluoroacetic anhydride (for deactivated aromatics). ${ }^{13}$ Even these systems, however, produce carboxylic acid as byproduct.

An alternative approach to clean nitration, pioneered by Suzuki et al., involves dinitrogen tetroxide and ozone, ${ }^{16}$ or dinitrogen tetroxide with oxygen and a catalyst. ${ }^{17}$ The use of oxygen rather than ozone was appealing and we demonstrated that use of zeolite $\mathrm{H} \beta$ as catalyst provided improved paraselectivity and easier catalyst recovery. ${ }^{18}$ However, the method still employed a large excess of dinitrogen tetroxide, a halogenated solvent, cooling and a reaction time of two days. Therefore, we continue to study the reaction in order to find ways of overcoming the remaining disadvantages. A recent publication from Suzuki et al. reveals that his group is also trying to perfect this zeolite-catalysed approach, ${ }^{19}$ and we now therefore disclose our own further findings.

Our initial objective was to improve our previous procedure ${ }^{18}$ by avoiding the need for cooling, decreasing the excess of dinitrogen tetroxide used and eliminating the solvent. These features were dictated by the volatility of dinitrogen tetroxide (bp $21^{\circ} \mathrm{C}$ ). Simply using an autoclave pressurised to $200 \mathrm{psi}$ with oxygen allowed a reaction with the desirable features to proceed quickly and in high yield. Furthermore, when oxygen was replaced by air the reaction was still efficient. With air it required about $12 \mathrm{~h}$ to go to completion, still quicker than under the previous conditions. ${ }^{18}$ By contrast, when the pressurising gas was nitrogen, virtually no nitration occurred, demonstrating the involvement of oxygen in the reaction.

It was not known whether the by-product was water, nitric acid or a mixture of the two. Eqn. (1) $(n=0-6)$ covers the various possible stoichiometries.

$24 \mathrm{ArH}+(12+2 n) \mathrm{N}_{2} \mathrm{O}_{4}+(6+n) \mathrm{O}_{2}=24 \mathrm{ArNO}_{2}+4 n \mathrm{HNO}_{3}$

$$
+(12-2 n) \mathrm{H}_{2} \mathrm{O}
$$

A series of reactions involving different proportions of chlorobenzene to dinitrogen tetroxide was allowed to react to completion ( 2 days). The results suggested that $3 \mathrm{~mol}$ of $\mathrm{ArH}$ react with 2 mol of $\mathrm{N}_{2} \mathrm{O}_{4}$ to give $3 \mathrm{~mol}$ of nitro product and 1 mol of $\mathrm{HNO}_{3}$ (eqn. (2), i.e. $n=2$ in eqn. (1)).

$$
3 \mathrm{ArH}+2 \mathrm{~N}_{2} \mathrm{O}_{4}+\mathrm{O}_{2}=3 \mathrm{ArNO}_{2}+\mathrm{HNO}_{3}+\mathrm{H}_{2} \mathrm{O}
$$

Various zeolites, with different pore structures, countercations and $\mathrm{Si}$ Al ratios, were examined under the new conditions. All zeolites tested catalysed the reaction and provided a modest increase in para-selectivity compared to reaction in the absence of catalyst. Zeolite $\mathrm{H} \beta$ was somewhat faster and gave greater para-selectivity than the others, but the differences were not major.

Zeolite $\mathrm{H} \beta$ was tested with a range of other substrates (Table 1). All substrates tested gave good yields of nitration products, with modest increases in the amounts of para-isomer in comparison with traditional methods. The relative reactivities did not appear to be consistent with a normal electrophilic aromatic substitution mechanism.

In an attempt to obtain further information about the system, we investigated the simple adsorption of $\mathrm{N}_{2} \mathrm{O}_{4}$ on zeolite $\mathrm{H} \beta$ as a function of temperature. The amount adsorbed dropped steadily as the temperature was increased, but there was still some adsorption even at $80{ }^{\circ} \mathrm{C}$ and the amount adsorbed at 20 ${ }^{\circ} \mathrm{C}$ was in the region of $1.53 \mathrm{mmol} \mathrm{N}_{2} \mathrm{O}_{4}$ per gram of zeolite. By employing excess zeolite we were able to conduct a reaction in ordinary glassware at $20{ }^{\circ} \mathrm{C}$ and near-atmospheric pressure, which enabled direct observation of the reaction mixture. Adsorption of $\mathrm{N}_{2} \mathrm{O}_{4}$ alone onto the zeolite imparted a pale brown hue to the solid. However, when benzene was allowed into the system, the colour of the adsorbed material immediately became much darker. Following admission of oxygen the reaction proceeded slowly to give nitrated product.

We speculate that the dark colour is indicative of an adsorbed intermediate formed by interaction of the substrate with $\mathrm{N}_{2} \mathrm{O}_{4}$,

Table 1 Nitration of various substrates with $\mathrm{N}_{2} \mathrm{O}_{4}$, zeolite $\mathrm{H} \beta$ and air ${ }^{a}$

\begin{tabular}{llc}
\hline Substrate & Yield $^{b}(\%)$ & $p / o$ ratio \\
\hline Toluene & 76 & 0.9 \\
Benzene & 97 & - \\
Fluorobenzene & 95 & 10.1 \\
Chlorobenzene & 97 & 5.6 \\
Bromobenzene & 90 & 4.2
\end{tabular}

${ }^{a}$ Reactions were carried out with zeolite $(3.0 \mathrm{~g})$, substrate $(33.0 \mathrm{mmol})$, and $\mathrm{N}_{2} \mathrm{O}_{4}$ (1.4 ml, ca. $23 \mathrm{mmol}$ ), under $200 \mathrm{psi}$ air pressure at room temperature. ${ }^{b}$ Calculated by quantitative GC. 
and that its conversion into product requires another reactive species to be formed more slowly between oxygen and the excess $\mathrm{N}_{2} \mathrm{O}_{4}$. The relative reactivities of different substrates and the small differences observed between the catalytic activities of proton and sodium forms of the same zeolites do not seem to be in line with an acid-catalysed electrophilic substitution reaction under these conditions. We therefore suspect that the reaction is radical in nature. Scheme 1 gives a tentative mechanism that is consistent with the stoichiometry. A similar overall result would be produced if $\mathrm{NO}_{2}$ radicals were to abstract the first hydrogen atoms and the $\mathrm{HNO}_{2}$ produced were then to react with oxygen to give $\mathrm{HOONO}_{2}$. However, in that event nitration would be expected in the absence of oxygen.

In previous reports of nitrations of aromatic compounds using dinitrogen tetroxide and zeolites in the absence of solvent, the reactions have been conducted at elevated temperatures in the gas phase..$^{20,21}$ It was assumed that the stoichiometry was as shown in eqn. (3) (c.f. eqn. (1) with $n=0$ ). If that were correct, it is likely that some of the product was formed by the action of nitric acid on the substrate at the elevated temperatures. Therefore, the reactions were likely to be complex and conclusions about the mechanisms based on the overall results need to be treated with caution.

$$
4 \mathrm{ArH}+2 \mathrm{~N}_{2} \mathrm{O}_{4}+\mathrm{O}_{2}=4 \mathrm{ArNO}_{2}+2 \mathrm{H}_{2} \mathrm{O}
$$

In the recent work of the Suzuki group, superior selectivities for production of para-isomers were achieved at low conversion using H-ZSM-5 as the zeolite and the substrate as its own solvent in the liquid phase. ${ }^{19}$ In the present work we have shown how it is possible to carry out the reaction to give high yields, with modest para-selectivities, without solvent, with only the stoichiometric quantity of dinitrogen tetroxide, using air instead of oxygen, and under mild conditions (ambient temperature and a modest pressure). Under these conditions the reaction is rather slow, but simply raising the temperature to $30-40{ }^{\circ} \mathrm{C}$ in the sealed system can reduce the required reaction period dramat-
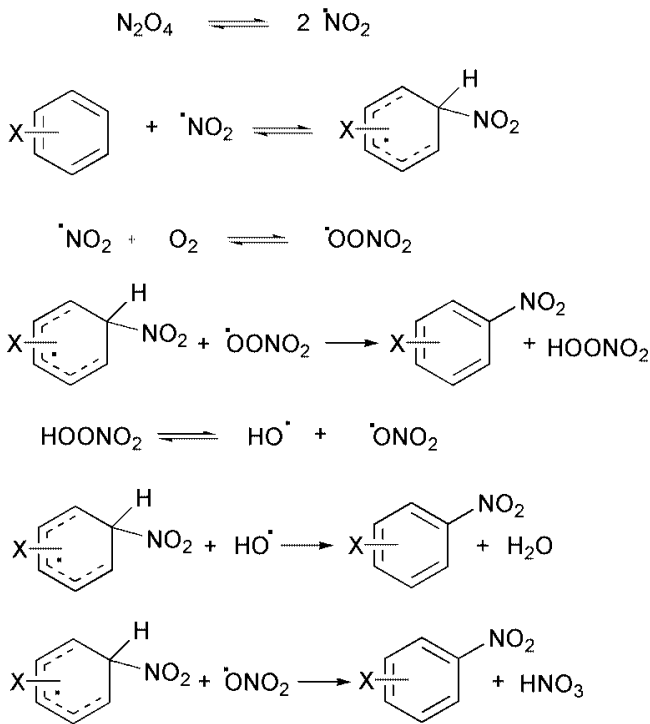

Scheme 1 A speculative mechanism for the reaction. Any or all of the step involving reaction of the substrate- $\mathrm{NO}_{2}$ adduct with another radical could proceed by either of two mechanisms: (i) direct hydrogen atom abstraction or (ii) electron abstraction to give a Wheland intermediate and an anion, followed by proton abstraction from the Wheland intermediate by the anion. Whether the zeolite would play an active part in catalysing any of the processes or merely assist through stabilisation of intermediates by adsorption is an open question. ically. Therefore, only two remaining obstacles prevent this reaction from fulfilling all the desired criteria. One is the relatively low para-selectivity (though already better than for traditional methods). The other is the production of a modest amount of nitric acid as by-product, which can deactivate the zeolite by adsorption or reaction, limits the efficiency of usage of the dinitrogen tetroxide feed and could lead to plant corrosion. We continue to search for ways to overcome these remaining disadvantages.

The reaction of chlorobenzene illustrates the general procedure for the nitration process. The zeolite $(3 \mathrm{~g})$ was placed in a $450 \mathrm{ml}$ autoclave, followed by chlorobenzene $(3.71 \mathrm{~g}, 33$ $\mathrm{mmol}$ ). Liquid dinitrogen tetroxide ( $c a .1 .4 \mathrm{ml}, c a .23 \mathrm{mmol}$ ) was added quickly to the mixture, the autoclave was sealed and pressurised to 200 psi with air, and the mixture was stirred at room temperature for $14 \mathrm{~h}$. The autoclave was then opened and the product was extracted with dichloromethane $(200 \mathrm{ml})$. The extract was washed with water $(50 \mathrm{ml})$, dried $\left(\mathrm{MgSO}_{4}\right)$ and concentrated under reduced pressure to give the product, which was analysed by GC (hexadecane was added as internal standard).

We thank Zeolyst International for gifts of zeolites and S. A. thanks the Government of Qatar for a studentship.

\section{Notes and references}

1 M. Butters, in Solid Supports and Catalysts in Organic Synthesis, ed. K Smith, Ellis Horwood, Chichester, 1992, pp. 130-170 J. M. Thomas and W. J. Thomas, Principles and Practice of Heterogeneous Catalysis, VCH, Weinheim, 1997 J. H. Clark, Catalysis of Organic Reactions Using Supported Inorganic Reagents, VCH, New York, 1994 Introduction to Zeolite Science and Practice, ed. H. Van Bekkum, E. M. Flanigan and J. C. Jansen, Stud. Surf. Sci. Catal., 1991, vol. 58.

2 K. Smith, M. Butters, W. E. Paget, D. Goubet, E. Fromentin and B. Nay, Green Chem., 1999, 1, 83.

3 K. Smith, P. He and A. Taylor, Green Chem., 1999, 1, 35.

4 K. Smith, Z. Zhenhua and P. K. G. Hodgson, J. Mol. Catal. A, 1998, 134, 121.

5 K. Smith, G. M. Ewart and K. R. Randles, J. Chem. Soc., Perkin Trans. $1,1997,1085$.

6 G. A. Olah, R. Malhotra and S. C. Narang, Nitration: Methods and Mechanisms, VCH, New York, 1989 K. Schofield, Aromatic Nitration, Cambridge University Press, Cambridge, 1980.

7 E. R Ward, Chem. Br., 1979, 15, 297.

8 K. Smith and K. Fry, Tetrahedron Lett., 1989, 5333.

9 R. P. Claridge, N. L. Lancaster, R. W. Millar, R. B. Moodie and J. P. B Sandall, J. Chem. Soc., Perkin Trans. 2, 1999, 1815.

10 T. J. Kwok, K. Jayasuriya, R. Damavarapu and B. W. Brodman, J. Org. Chem., 1994, 59, 4939.

11 J. M. Bakka, U.K. Pat. Appl., 7827172, 1979B. M. Choudary, M. Sateesh, M. L. Kantam, K. K. Rao, K. V. R. Prasad, K. V. Raghavan and J. A. R. P. Sarma, Chem. Commun., 2000, 25; D. Vassena, A Kogelbaner and R. Prins, Catal. Today, 2000, 275.

12 K. Smith, A. Musson and G. A. DeBoos, J. Org. Chem., 1998, 63, 8448 .

13 K. Smith, T. Gibbins, R. W. Millar and R. P. Claridge, J. Chem. Soc., Perkin Trans. 1, 2000, 2753.

14 F. J. Waller, A. G. M. Barrett, D. C. Braddock and D. Ramprasad, Chem. Commun., 1997, 613.

15 M. Dove, B. Manz, J. Montgomery, G. Pattenden and S. Wood, J. Chem. Soc., Perkin Trans. 1, 1998, 1589.

16 H. Suzuki and T. Mori, J. Chem. Soc., Perkin Trans. 2, 1994, 479.

17 H. Suzuki, S. Yonezawa, N. Nonoyama and T. Mori, J. Chem. Soc., Perkin Trans. 1, 1996, 2385.

18 K. Smith, S. Almeer and S. J. Black, Chem. Commun., 2000, 1571.

19 X. Peng, H. Suzuki and C. Lu, Tetrahedron Lett., 2001, 42, 4357.

20 A. Germain, T. Akouz and F. Figueras, Appl. Catal. A: Gen., 1996, 136, 57.

21 N. F. Salakhutdinov, K. G. Ione, E. A. Kobzar and L. V. Malysheva, Russ. J. Org. Chem., 1993, 29, 457 